\title{
Multimedia Competencies for University Staff to Empower Manufacturing Science Education
}

\author{
Anca Draghici ${ }^{1 *}$ \\ ${ }^{1}$ Politehnica University of Timisoara, Faculty of Management in Production and Transportation, \\ 14. Remus str., 300191 Timisoara, Romania
}

\begin{abstract}
The paper aims describing a collaborative international initiative of four European universities to develop a training program for supporting university staff in creating and using multimedia resources effectively. Thus, teaching, researcher and administrative staff from higher education institutions will develop their digital skills to create more realistic and attractive content that should improve university prestige through a better communication process with the stakeholders. We relate the presented approach to MUST project (Multimedia Competencies for University Staff to Empower University - Community Collaborations, 2020-1-RO01-KA203-080399), that aims develop and implement a new multimedia curriculum and training program. The training curriculum and the created educational resources make up a dedicated service offered by universities through DigiCoaches who will provide training to other internal/external users/trainees in creating-using multimedia technologies effectively.
\end{abstract}

\section{Introduction}

COVID-19 pandemic has paralyzed the education process, the education institutions all over the Globe. According to the available data provided by UNESCO through the online Global Monitoring of Schools Closures Caused by Covid-19 [1,2] the situation is unimaginable: more than 1,600,000,000 affected learners all around the World; $90,2 \%$ of total enrolled learners World-Wide that are affected and 191 country-wide closures with education entities close. Educators, trainers, teachers, coaches, or mentors face unprecedented challenge of ensuring that education continues, even during a long period when students must remain at home. Some extraordinary facts for education in 2020 were $[1-3]$ :

- Till now, there have not been used the indicator number of closed schools to characterize the educational process!

- Till now, there have not been restricted the access to education, culture, and art institutions, including libraries and other learning life experiential hubs for such an extended area of the Globe and for such many people!

\footnotetext{
*Corresponding author: author@email.org
} 
- We are confronted with a high autonomy in providing teaching and learning activities online, virtually using new technologies!

This unprecedent facts has been cased because instantly [3]:

- Universities were moved (pushed) on-line and thus, they were confronted with a knowledge, resources, and technology gap (including personal computers/devices and Internet availability for everyone, educational resources available, the information and communication technology, less personal support etc.), but also managerial gap, too!

- Teaching staff and learners' digital competencies value a lot, and it was the main condition for continuing studying, having access to education resources, collaborations.

There is a knowledge gap of research on using multimedia technologies and knowledge in engineering, health care services, nursing, information sciences, social sciences (as management, marketing, sustainable development management etc.), linguistics (1\%-2\%). These were subjects of various statistics and studies, and the most interesting fact has been depicted in Figure 1 [4]. The data shows a gap of using multimedia resources in engineering, information sciences, nursing and health care services, physics and other fields, situation that was not expected and that needs special attention in terms of intensive trainings programs for teaching and research staff (mainly affected by this gap) [4]. The echoes of this knowledge gap have been identified in employees' engagement and their capacity of knowledge sharing for supporting organizational performance during the pandemic crisis [5].

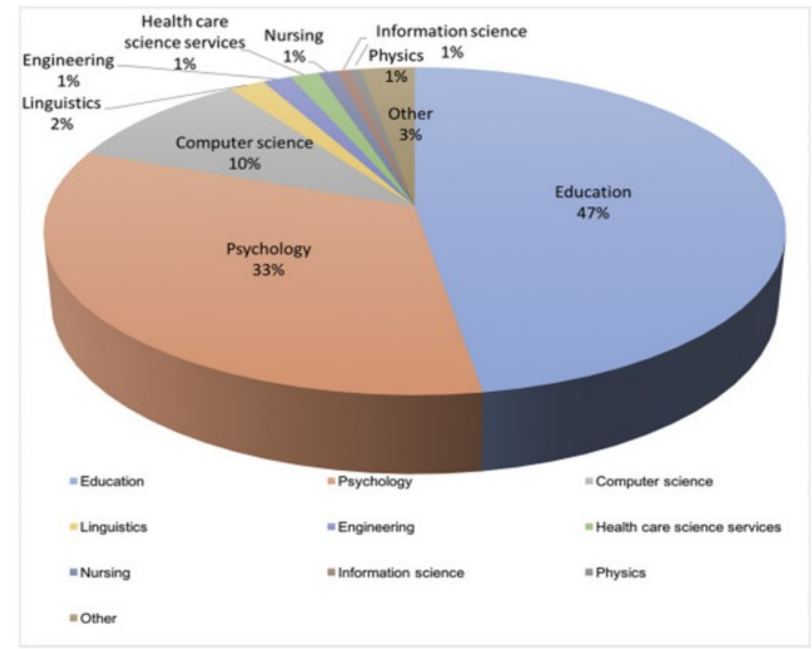

Fig. 1. Scientific and economic domains that uses/exploit multimedia resources (for education, learning, research and development, marketing etc.) as find by [4].

Furthermore, there have been recognized the teaching staff professional metamorphosis a process that is related to biology and which is associated with a metaphor in this case (means a striking change in appearance or character or circumstances). Teaching staff has suffered a disruptive, abrupt change on how they act, being most affected in the pedagogical field (methods and tools used offline are different with those use online a most because of the communication process) where were registered most of their knowledge gaps and complains, together with globally expressed requirement on support from specialists (requirements from teachers of all educational levels) [5-8]. From the practical 
perspective, teaching staff metamorphosis was associated with the shift and balance (in some periods) between (Education and Research) and (e-Teaching and e-Research), or even simpler from traditional in-door activities to e-activities with students, colleagues, administrative staff, and other stakeholders.

In this context, there have been developed the present research for the motivation of "building" the MUST project. The paper aims describing a collaborative international initiative of four European universities to develop a training program for supporting university staff in creating and using multimedia resources effectively. Thus, teaching, researcher and administrative staff from higher education institutions will develop their digital skills to create more realistic and attractive content that should improve university prestige through a better communication process with the stakeholders. The created international consortium will support the new multimedia curriculum and training program development which will fill the knowledge gap underlined by [4]. MUST training curriculum and the created educational resources will be exploited as a dedicated service offered by universities through DigiCoaches (trainers of trainers) who will provide training to other internal/external users/trainees in using multimedia technologies effectively.

\section{Teaching engineering online - literature review}

In the pandemic period there have been arisen a huge need for improving and develop teaching staff digital competencies and in extension, for all university staff. There have been observed that administrative staff have been leaved "alone" with discrete support in some periods given by the technical staff or teachers. The training need for technical support and new pedagogic methods for online education have been the main requirements of the studies developed during the pandemic of Covid-19 period [9, 10]. Furthermore, there have been an intensive debate on the difficulties in teaching engineering online (Figure 2).

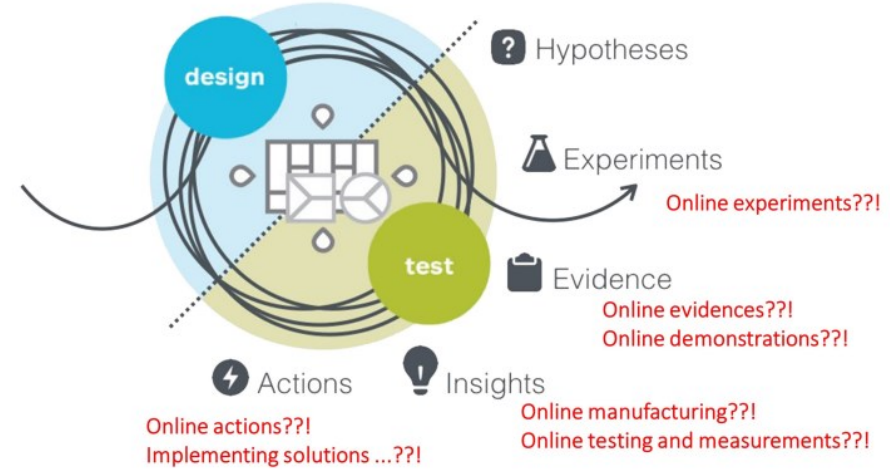

Fig. 2. Difficulties of teaching and learning engineering design online.

Only if considering the engineering design stages, difficulties occurred in experiments, evidence, insights, and action phases, as shown in Figure 2, and these is because access to the laboratories, MakerSpaces and FabLabs has been forbidden or limited to teaching and technical staff only, thus generally, access to university infrastructure and to companies for internships have been restricted $[11,12]$. Thus, trainers have been pushed to develop "new models for teaching physical prototyping, electronics production, and digital fabrication at a distance. Instructors shipped materials and equipment directly to students, converted makerspaces to job-shops, and substituted low-tech construction methods and hobbyist equipment for industrial tools. The experiences of students and instructors during the 
pandemic highlighted new learning opportunities when making outside the makerspace. Simultaneously, the shutdown raised new questions on the limits of remote learning for digital fabrication, electronics, and manual craft" [12]. In addition to this way of doing engineering education, teaching and technical staff access the universities' laboratories infrastructure and provided demonstrations through multimedia materials (used as educational resources), using short movies and demos as educational resources. Usually, they use their mobile phones and exploit their own abilities in acting (teaching and technical staff were developed movies on specific engineering topics that were presented via online) [13-15].

Project and/or problem-based learning methods were generally supported by collaborative working platforms such as Google Drive or OneDrive from Microsoft, with links available for students and trainers, too. Beside these, students' periodical or final assessments or knowledge verification of their self-learning have been done quizzes, with the possibility to check and improve the answers or using brief ideas presentations upload on the virtual space usually developed using the facilities of the Moodle platform [14].

The operational problems that arise during the process of teaching - learning engineering subjects online were accompanying by technical difficulties as Internet connection or signal and in some areas, lack of electric energy sometime. Despite other educational level, majority of the students from higher education have a computer and a mobile phone thus, learning and working online was not affected by this situation.

\section{Multimedia Competencies for University Staff}

\subsection{Overview of MUST Project}

MUST project (Multimedia Competencies for University Staff to Empower University Community Collaborations) addresses to "Innovative practices in a digital era" (as described in [16], p. 101), because it proposes to develop and implement an innovative blended curriculum and training program dedicated to university staff to support their multimedia skills development; these refer to the design and use of digital technologies in creative, collaborative, efficient ways to better facilitate teaching-training-learningassessment process of Generation Z students or for user in universities' community (vocational education for lifelong learning). These are aligned with the objectives of the European Education Area, notably the new European Universities initiative [17]. Considering the European Commission Digital Education Action Plan [18] that calls for systematic action in this area, MUST project addresses to the developing of digital competences and skills (Actions 4 to 8 ) and the use of the European frameworks on digital competences of educators as university staff.

In each university partner involved in the project there were not implemented coherent training programs for multimedia skills development of teaching staff (as will be demonstrated through the training needs assessment). The developed high quality visual digital media resources and learning framework can help to engage this target group in meaningful learning activities for self-expression and gradual competence and confidence building in key competences as well as the technical skills to use sector specific occupational learning. Visual media within a transmedia strategy make learning independent of time, allow for repeating the content as needed and can be designed to promote language proficiency, digital skills, a sense of initiative and self-efficacy at the same time. Common projects using engaging multimedia with university staff and students/community learners can lower the mental barriers for accessing higher education [19]. 
The project is developed in an international consortium, because none of the participating university has enough expertise available to carry out the programme on its own (as demonstrated also by the Pilot Study developed in 2020 before the project submission) and they need support from expertise of an NGO partner from Germany (SoWiBeFo) and a small company from Portugal (Storytellme). Benchmarking expertise on work based learning and digital media developed in Germany (referring to universities and industry) and experiences from the use of text-based digital learning in Portugal will enriched and extend university staff knowledge in the design and use of multimedia technologies [19]. Project details and the international partnership are described on the project's web page: https://mustproject.eu/.

The project objectives are to improve and diversify: (1) university staff skills in creating and using multimedia technologies effectively (for education, research, universitycommunity projects, advertising, and communication purposes); (2) the services offered to university users and other university staff through the designed training program that empower these users with key skills and the opportunity to develop their multimedia competencies. Following MUST training program, skilled university staff could better support not only internal processes of the universities but also university-community project by creating a strong imagine (through visual storytelling, experiments, and demonstrations, through transmedia etc.) on the academic potential for knowledgeinnovation transfer, lifelong learning and vocational education training, social and cultural projects, university advertising etc. The developed MUST training curriculum and the created educational resources will define a dedicated service offered by universities through DigiCoaches (trainers of trainers from university staff) who will provide training to other internal/external users/trainees in creating-using multimedia technologies effectively.

\subsection{Research on Multimedia Training Needs Assessment}

A survey based on a designed questionnaire was conducted supported by the Google Form platform; the answers were collected from January 2021 to April 2021. This study was applied online and addressed to individuals from the universities from Romania, Germany, Lithuania, North Macedonia, and Slovenia. The research sample consists of all types of universities staff (teaching, administrative, technical, students); 122 responses were registered, being representative for the targeted university. From the perspective of age, there are respondents in the category under 25 years, approximately $27 \%$, the interval between 25 and 35 years there were $15 \%$, the interval $35-45$ years a percentage of $30 \%$, and over 45 years a percentage of $26 \%$. From a gender perspective, there is a well-balanced proportion, about $53 \%$ women, and $47 \%$ male. The areas in which the respondents work, and they will exploit the achieved multimedia knowledge is manly from the engineering field of science $(51.70 \%)$.

Figure 3 shows the results regarding the respondents' interest on several topics to get involved in such training programs. The skills held are suitable for the job, but they can be improved. Respondents are willing to improve their multimedia skills because they can strengthen both research and practical skills.

Figure 4 highlights the respondents' training needs in multimedia production and exploitation fields. There is interest in a "strong" and "very strong" need for knowledge exploitation. From the general basic knowledge perspective, the directions targeted by this research were: relevant intellectual property rights in the context of multimedia design, production and exploitation, planning strategies for multimedia design, multimedia production techniques, and methods and tools used in multimedia production. Respondents were most interested in the multimedia applications for supporting education processes (knowledge gap identified by the literature review, also). In addition, the preferred method 
for achieving multimedia skills and competence has been investigated. Over $46 \%$ appreciate that best practices represent the main direction. Tutorial demonstrations are appreciated by $31 \%$ of respondents.

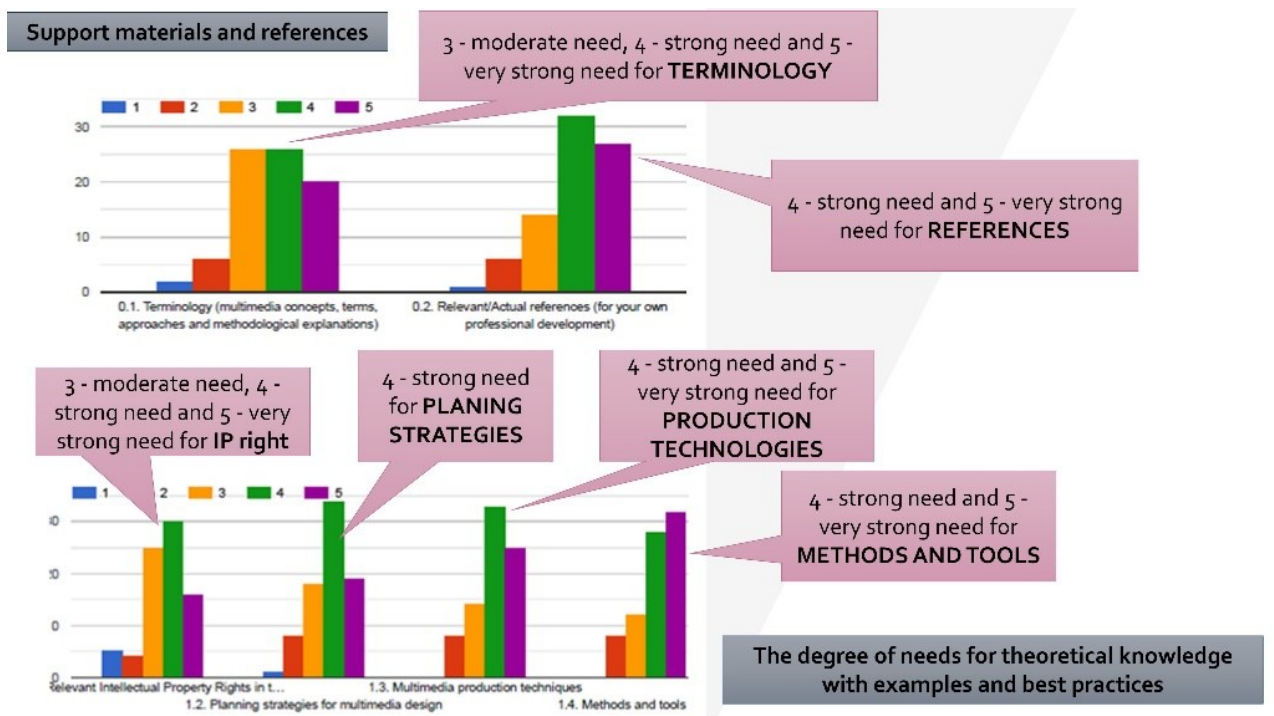

Fig. 3. The responses reflecting the need for "Support material and Reference" and for theoretical knowledge in different areas.

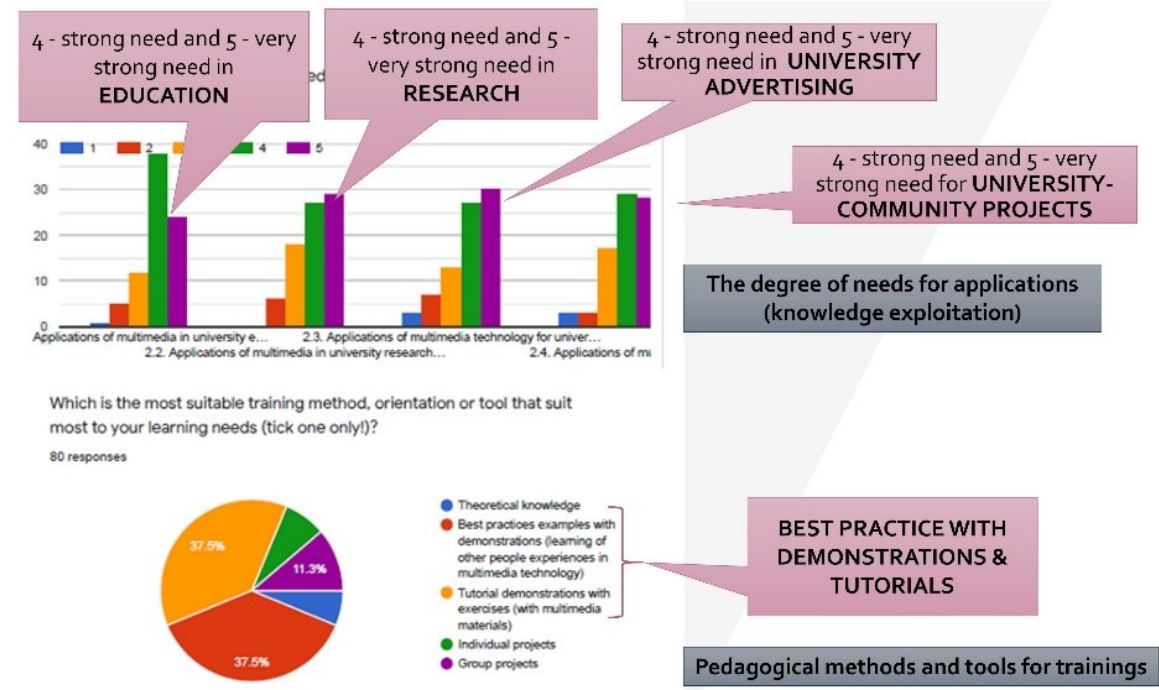

Fig. 4. Respondents' interest in getting involved in a program for developing multimedia skills.

\section{MUST Framework for Multimedia Competences Development}

Preliminary study has been developed with the support of MUST project consortium for creating a taxonomy of digital competences to be addressed by the future training program. Also, there have been established a general framework of action in defining MUST training program, as seen in Figure 5. 


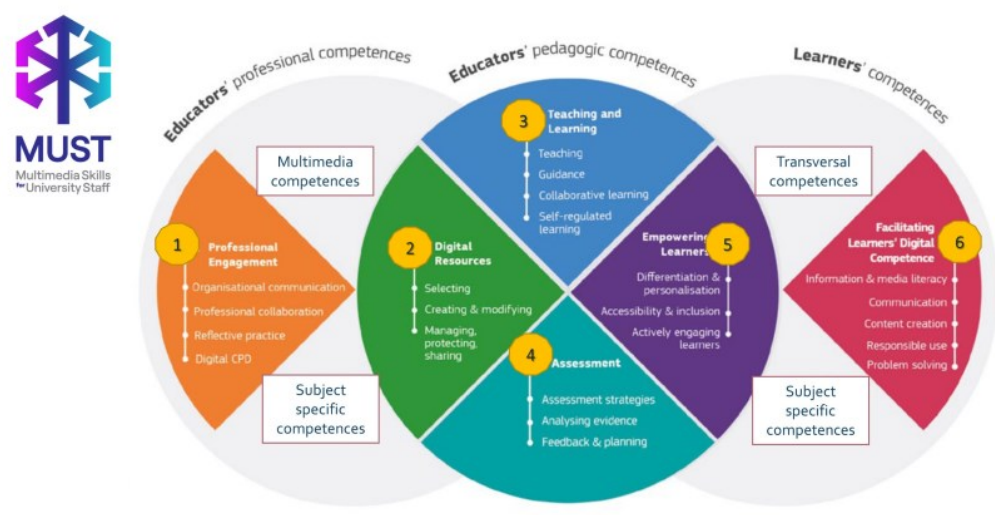

Fig. 5. MUST general framework descriptin.

As seen in Figure 5, the general framework consists of six stages that support three areas of multimedia competences development: (1) support educator's professional competence development (referring to the DigiCoaches); (2) Educators' pedagogic competences development (referring to the DigiCoaches) and (3) Learners' competences development, (referring to the university staff of all categories which will be trained.

Finally, the proposed framework for multimedia skills development has been developed based on the Bloom's taxonomy (adapted for https://cft.vanderbilt.edu/guides-subpages/blooms-taxonomy/). The adaptation takes into considerations five levels of the taxonomy by merging level 1 and 2 of the original shape due to the way learning and action (knowledge use and exploitation) in the case of multimedia technologies required such an approach. According to this framework, a preliminary self-assessment test provides a diagnosis, feed-back of the potential trainers' skills and competences (done online via the web page and the e-learning platform dedicated to MUST training program) to the design and development of the multimedia products (see Table 1 and Figure 6).

The self-assessment test offers concrete suggestions for competence improvement in a specific domain (related to the training units of the designed training program). Moreover, university staff will get the opportunity to increase their competence level by enrolling in the corresponding online training program that will be developed by MUST consortium. Depending on the identified proficiency level, potential trainers might be suggested to complete either the entire training or only specific unit(s). Each area is assessed independently; individuals although can freely choose any area, he/she should assess the five areas sequentially, using the same scale as suggested by the Blooms' taxonomy (individuals should choose the option that best fits to his/her competence level).

After the self-assessment is finalized, potential trainers will be given general feedback in terms of his/her competence level for the whole area (unit) and each related traininglearning element (which correspond to a specific competence that is developed) in certain cases he/she will be pointed to the right training modules that should be followed to further develop his/her competence level (see the case described in Figure 6). The Virtual Campus of Politehnica University of Timisoara, Romania will be the host of the MUST training program (a multilingual training) and the created educational resources and tools will be available on projects web page, too (https://mustproject.eu/).

The described framework is correlated with the training program skill card (units are described in the first column of Table 1). The total number of competencies is 18 and they refer both to the Pedagogy and Technology domains (as identified by MUST consortium members); these were considered most relevant for the creation and delivery of the MUST training program for university staff (and will allow the transformation into a post- 
university training program). The defined competencies (associated to the training elements of each unit) were also verified by participants in two focus groups consisting of academic staff and instructional designers from partner institutions in Slovenia, Lithuania, Portugal, Germany, Spain, North Macedonia, and Romania. Thus, MUST training program is already structured for the university staff (including teaching, research, and administrative staff) multimedia skills development. In the next period there will be developed the in Europe and beyond will receive accurate input on the development and implementation of MOOC-based curricula. MUST training program itself will be designed as a MOOC in English language and it will be translated in all university partners languages. In this way, the wider international academic community will be granted with open access to this output and will learn about multimedia design and technologies.

Table 1. Details on the designed self-assessment test related to multimedia competencies.

\begin{tabular}{|c|c|c|}
\hline $\begin{array}{l}\text { Area of competences to be } \\
\text { assess (training units) }\end{array}$ & $\begin{array}{l}\text { Evaluation scale (derived from } \\
\text { Bloom's taxonomy) }\end{array}$ & $\begin{array}{l}\text { Test results and } \\
\text { recommendations }\end{array}$ \\
\hline $\begin{array}{l}\text { (U1) Intellectual Property Rights } \\
\text { for multimedia }\end{array}$ & \multirow{5}{*}{$\begin{array}{l}\text { 1. I have basic knowledge and } \\
\text { hear about which allow me to } \\
\text { explain the basic principles of ... } \\
\text { 2. I can design a multimedia } \\
\text { product and apply knowledge for } \\
\ldots \text { I } \\
\text { 3. I developed analysis and } \\
\text { synthesis based on the knowledge } \\
\text { in the field of ...; I can design a } \\
\text { approach for ... } \\
\text { 4. I can evaluate ... } \\
5 . \quad \text { I can create professional ... } \\
6 \text {. No statement is correct. }\end{array}$} & \multirow{5}{*}{$\begin{array}{l}\text { - Feed-back for } \\
\text { each training } \\
\text { element } \\
\text { - General } \\
\text { feedback } \\
\text { training unit per } \\
\text { suggestion on which } \\
\text { element and unit } \\
\text { should be followed }\end{array}$} \\
\hline $\begin{array}{l}\text { (U2) Planning strategies for } \\
\text { multimedia design }\end{array}$ & & \\
\hline $\begin{array}{l}\text { (U3) Multimedia production } \\
\text { techniques }\end{array}$ & & \\
\hline $\begin{array}{l}\text { (U4) Methods and tools for } \\
\text { multimedia production }\end{array}$ & & \\
\hline $\begin{array}{l}\text { (U5) Applicative competences } \\
\text { (education, research, advertising, } \\
\text { community projects) }\end{array}$ & & \\
\hline
\end{tabular}
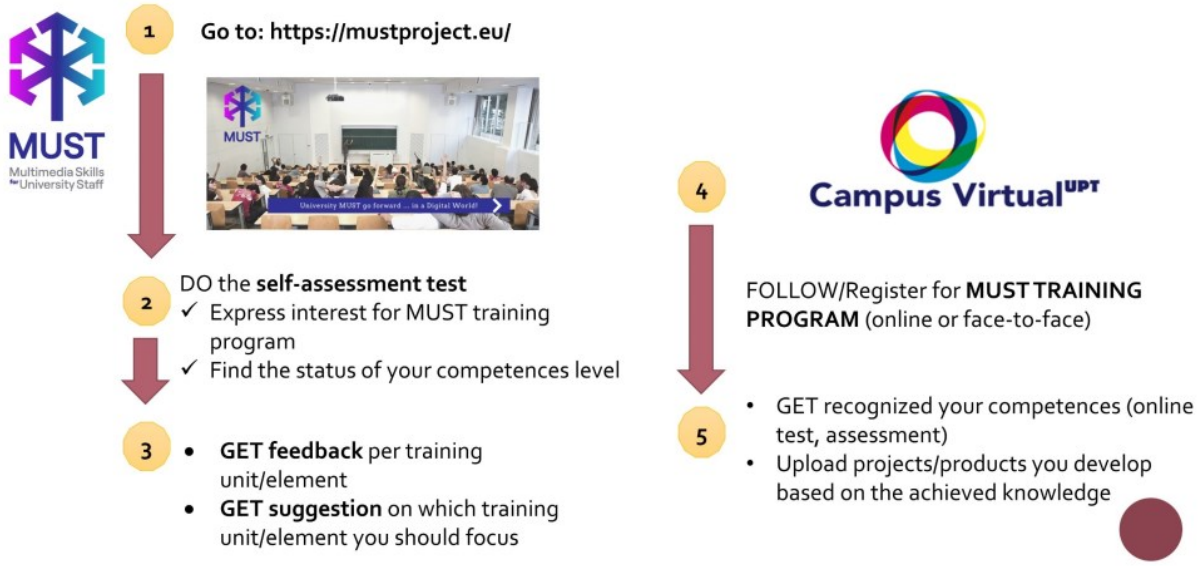

Fig. 6. MUST framework implementation at Politehnica University of Timisoara, Romania.

\section{Conclusions}

The pandemic situation has changed the way education is developed, has dramatical change the way in which university staff develop their didactic, research activities, and the way they interact with community stakeholders in different projects or initiatives, too. The inventory of challenges is not stable because of the "new normal" conditions that will 
define the post-pandemic period. It is obvious that universities have accelerated their digital transformation, and this is major advantage from the general adoption of the online education (including the created infrastructure and the maintenance structures). Thus, universities' managers have discovered the advantages (e.g., buildings maintenance cost reduction, improve resources efficiency, improve facility management globally etc.) of using in a new way the real, offline infrastructure and the online one, by approving blending and hybrid activities supported by well trained staff ready to support the development of the $21^{\text {st }}$ century (future) skills.

Nowadays, university staff is invited to seriously considered learning, un-learning, and re-learning processes most in the lifelong learning or vocational learning context. Competency building needs to be strengthened through multimedia technology training programs. MUST project is an opportunity and a necessity for engineering education and not only. In the context of the paper, the training needs for multimedia skills were identified through an online study conducted with the support of respondents from the organizations' partners in the MUST project (Romania, Germany, Lithuania, North Macedonia, Portugal, Spain, and Slovenia). Respondents (university staff) have considered that "practical studies and simulations" that can be performed using these technologies.

Strengthening multimedia skills is a necessity in the pandemic and post-pandemic conditions of teaching and learning where online activities have replaced the traditional face-to-face learning; multimedia resources could empower the teaching process and could create more realistic experiences to future engineering in understanding different approaches related to different subject of study. In addition, university teaching staff skills' development in the field of multimedia can attract students in the teaching process and increase the motivation rate (develop active learning communities). It is expected that the proposed approach of skills development will positively impact students' way of communication and better expressed themselves.

In the next period, the content development related to the training units and elements will contributed to the presented framework enrichment and practical transfer. Thus, a study on the generated effects (feed-back collected) of the learning program is needed to really proof the impact of the achieved skills in engineering studies (promoting best practices, successful pedagogical methods etc.).

The paper is linked with the research and dissemination activities related to the MUST project: "Multimedia Competencies for University Staff to Empower University - Community Collaborations" (Erasmus+ 2020-1-RO01-KA203-080399), founded with support of the European Commission. This paper and the communication reflect the views only of the authors, and the Commission cannot be held responsible for any use, which may be made of the information contained therein.

\section{References}

1. UNESCO, Education: From disruption to recovery. Retrieved from: https://en.unesco.org/covid19/educationresponse (Access on April 14, 2020)

2. UNESCO, \#LearningNeverStops. COVID-19 education response. Paris: UNESCO. https://en.unesco.org/covid19/educationresponse/globalcoalition (Access on April 28, 2020)

3. A. Draghici, Human Systems Management, 39(4), 469-472, (2020)

4. J. Li, P. D Antonenko, J. Wang. Educational Research Review, 100282 (2019)

5. T. Ahmed, M. Shahid Khan, D. Thitivesa, Y. Siraphatthada, T. Phumdara. Human Systems Management, 39(4), 589-601 (2020)

6. A. Davis, R.G. Mirick. Journal of Social Work Education, 1-17, (2021) 
7. L. M. Bidwell, S.T. Grether, J. Pederson. Disruption and difficulty: Student and faculty perceptions of the transition to online instruction in the COVID-19 pandemic. In COVID-19 (pp. 31-46). Routledge (2020)

8. S. Popa. Reflections on COVID-19 and the future of education and learning, Prospects, 49, 1-6 (2020)

9. D. S. V. Bhuvaneswari Balachander, U. Sadasivan. Psychology and Education Journal, 57(9), 1461-1472 (2020).

10. A. Bozkurt, I. Jung, J. Xiao, V. Vladimirschi, R. Schuwer, G. Egorov, ... M. Paskevicius. Asian Journal of Distance Education, 15(1), 1-126 (2020)

11. M. Kinnula, I.S. Milara, B. Norouzi, S. Sharma, N. Iivari. International Journal of Child-Computer Interaction, 29, 100303 (2021)

12. P. C. Herrera, C. Dreifuss-Serrano, B. Juarez. Strategic Design Research Journal, 14(1), 236-251 (2021)

13. V. Revilla-Cuesta, M. Skaf, J.M. Varona, V. Ortega-López. International Journal of Environmental Research and Public Health, 18(4), 2127 (2021)

14. A. Ożadowicz. Education Sciences, 10(10), 292 (2020)

15. V. Ripoll, M. Godino-Ojer, J. Calzada. Education for Chemical Engineers, 34, 94-105 (2021)

16. X. Ren, J. Cui. Journal of Testing and Evaluation (2021)

17. X. Shi. International Journal of Emerging Technologies in Learning (2017)

18. Y. Shu. Experimental data analysis of college english teaching based on computer multimedia technology. Computer-Aided Design and Applications (2020)

19. A. E. Rakhimova, A.F. Mukhamadiarova. Multimedia technologies as an educational environment in the formation of sociocultural competence. Opcion (2020) 